\title{
Acute life-threatening intraoperative atelectasis
}

$A$ case is presented of acute intraoperative atelectasis causing profound hypoxaemia in a patient undergoing a combined epidural-general anaesthetic for hip surgery in the lateral position. The pathophysiology of the resultant ventilation-perfusion mismatch and the effects of applied positive end-expiratory pressure in the lateral position are explored. The emergency management is assessed, with emphasis on the role of bronchoscopy in diagnosis and treatment of this rare cause of life-threatening hypoxaemia in the operating room. This patient with risk factors for respiratory complications may have benefited from preoperative bronchoscopy to assist in lung expansion.

On présente ici un cas d'atélectasie peropératoire aiguë provoquant une hypoxémie profonde chez un patient soumis à une anesthésie épidurale associée à une générale pour une chirurgie de la hanche en position latérale. La physiopathologie de la dysharmonie ventilation-perfusion qui en est résultée et les effets de la pression téléexpiratoire qui fut appliquée en position latérale sont analysés. Le traitement d'urgence est évalué en mettant en relief le rôle de la bronchoscopie utilisée pour diagnostiquer et traiter cette cause rare d'hypoxémie grave en salle d'opération. Ce patient qui présentait des facteurs de risque de complications respiratoires aurait pu bénéficier d'une bronchoscopie préopératoire pour permettre l'expansion pulmonaire.

\section{Key words}

ANAESTHETIC TECHNIQUES: endotracheal, bronchoscopy; COMPLICATIONS: atelectasis; HYPOXIA.

From the Department of Anesthesiology, University of Texas Medical School at Houston.

Address correspondence to: Dr. Evan G. Pivalizza,

Department of Anesthesiology, University of Texas Medical

School, 6431 Fannin, MSMB 5.020, Houston, Texas 77030.

Accepted for publication 28th April, 1994.
Causes of intraoperative hypoxaemia may involve an increase in ventilation-perfusion $(\dot{V} / \dot{Q})$ inequality.' Severe pulmonary atelectasis, although occurring in up to $2.8 \%$ of patients after general anaesthesia, ${ }^{2}$ is an extremely rare cause of severe life-threatening intraoperative hypoxaemia. ${ }^{3}$ We report a case of a patient with acute intraoperative atelectasis and profound hypoxaemia, and discuss the management thereof.

\section{Case report}

The patient, a 50-yr-old, 70-kg man was presented for open reduction and internal fixation (ORIF) of the right acetabulum. Twelve days previously he had been injured in an automobile accident and at another hospital underwent exploratory laparotomy for a suspected rupture of the left hemi-diaphragm and possible visceral injury. The chest $x$-ray (CXR) showed the stomach bubble and splenic flexure in the lower left chest with no sharply demarcated diaphragmatic surface. However, the diaphragm was found to be intact, a superficial liver laceration had stopped bleeding and a pelvic haematoma was noted from a right acetabular fracture. In view of these findings, a congenital eventration of the diaphragm was diagnosed. The lungs were ventilated for $24 \mathrm{hr}$ postoperatively. Five days after the initial injury the patient was transferred to our institution for further orthopaedic management.

Preoperative assessment (11 days post-injury) revealed a 100 pack year smoking history and two previous general anaesthetics without known respiratory complications, a respiratory rate of 20 , absent air entry to auscultation at the left base, and on CXR, a persistently elevated and poorly visualized left diaphragm with small bilateral pleural effusions, despite intermittent positivepressure breathing (IPPB) and albuterol therapy (Figure 1). Other medications included ranitidine and acetaminophen. On the day before surgery, a spot oxygen saturation check $\left(\mathrm{SpO}_{2}\right)$ was $100 \%$ whilst breathing $2 \mathrm{~L}$ $\mathrm{O}_{2}$ by nasal cannulae. Haemotological variables and electrolytes were normal. The following morning an epidural catheter was placed at the $\mathrm{L}_{3-4}$ level. A sensory level at $\mathrm{T}_{8}$ was achieved with $6 \mathrm{ml}$ lidocaine $2 \%$ and subsequent addition of $25 \mathrm{ml}$ bupivacaine $0.5 \%$. On transfer to the operating room $(\mathrm{OR})$ the patient was lying supine without 


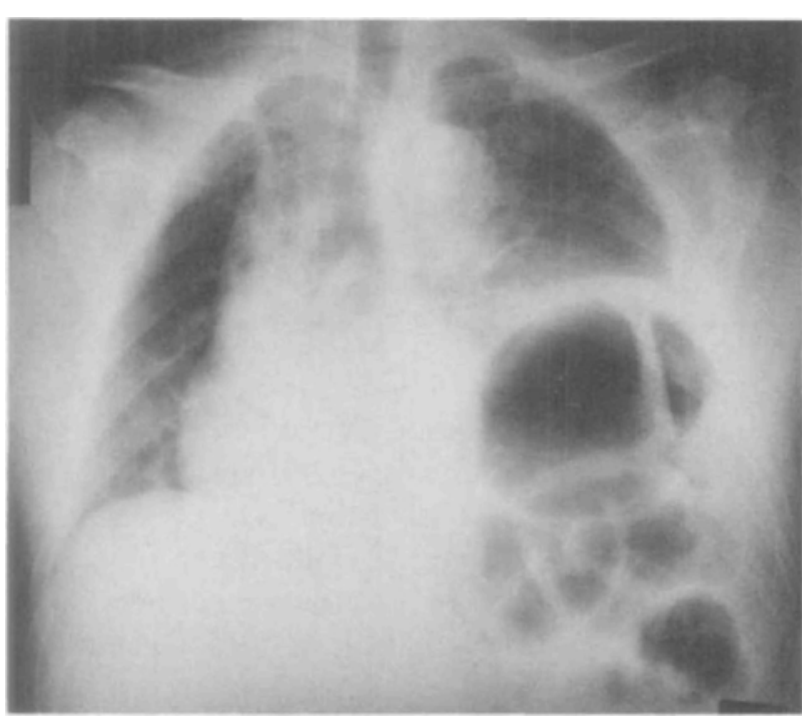

FIGURE 1 Preoperative chest $x$-ray.

distress but $\mathrm{SpO}_{2}$ was $86 \%$ breathing room air, heart rate (HR) was $102 \mathrm{bpm}$ and NIBP was $150 / 85 \mathrm{mmHg}$. While breathing $100 \% \mathrm{O}_{2}, \mathrm{SpO}_{2}$ increased to $99 \%$. In view of the low $\mathrm{SpO}_{2}$, lateral position required for surgery and persistent CXR findings, it was decided to intubate the trachea to facilitate intermittent positive-pressure ventilation (IPPV) with positive end expiratory pressure (PEEP) and pulmonary toilet.

General anaesthesia was induced with fentanyl $250 \mu \mathrm{g}$ and etomidate $24 \mathrm{mg}$. Tracheal intubation with a $8.5 \mathrm{~mm}$ endotracheal tube (ETT) was facilitated with succinylcholine $100 \mathrm{mg}$. Cricoid pressure was maintained until ETT position was confirmed. Breath sounds were present bilaterally but absent at left base. A nasogastric tube was passed to decompress the stomach. Anaesthesia was maintained with isoflurane in $40 \% \mathrm{O}_{2}$ after neuromuscular blockade with vecuronium. The $\mathrm{SpO}_{2}$ was $94-96 \%$. Within $25 \mathrm{~min}$ of transfer to the left lateral position for surgery $\mathrm{SpO}_{2}$ decreased to $85 \%$, despite increasing $\mathrm{FIO}_{2}$ to 1.0. Auscultation revealed absent breath sounds at the left base with poor apical air entry as well. Arterial blood gas analyses demonstrated $\mathrm{PaO}_{2}$ of $48-54 \mathrm{mmHg}$ with $\mathrm{PaCO}_{2}$ of $56-58 \mathrm{mmHg}$ and $\mathrm{pH}$ of 7.32. The ETT was suctioned and pulled back $2 \mathrm{~cm}$ and manipulations of tidal volume ( $\left.\mathrm{V}_{\mathrm{T}}\right), \mathrm{PEEP}$ (to $15 \mathrm{~cm}$ water) and manual ventilation to airway pressures of $45-50 \mathrm{~cm}$ water did not improve $\mathrm{SpO}_{2}$, As ventilation remained difficult, fibreoptic bronchoscopy was done. Correct ETT position was confirmed, the right bronchi were clear and both the left upper (LUL) and lower (LLL) bronchi were draining tenacious white secretions which were aspirated. For $20 \mathrm{~min}$ preceding and during bronchoscopy the $\mathrm{SpO}_{2}$

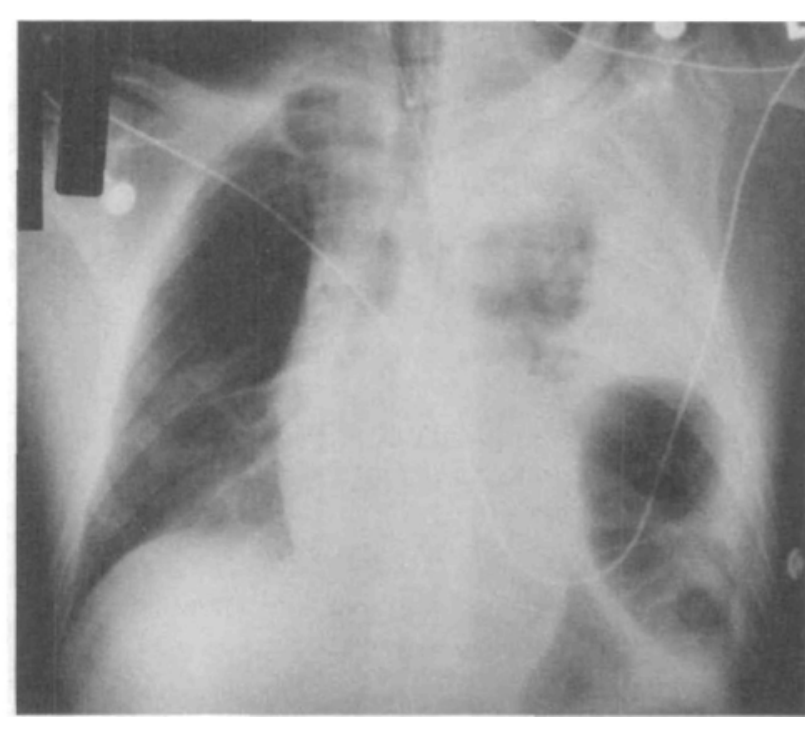

FIGURE 2 Immediate postoperative chest $x$-ray in the operating room.

had decreased to 60-70\% and did not improve after bronchoscopy. Ephedrine, $50 \mathrm{mg}$, and phenylephrine, $300 \mu \mathrm{g}$, were required to maintain mean arterial pressure $>60$ mmHg. The surgeons rapidly concluded surgery and the patient was placed in the supine position. An immediate CXR showed widespread opacification of the left hemithorax with decrease of the left lung volume (Figure 2). The trauma surgeons who had been summoned due to the possibility of an acute diaphragmatic rupture (as well as suspected atelectasis), repeated bronchoscopy. Thick mucus in the LUL and LLL bronchi was aspirated again with extensive saline lavage. The $\mathrm{SpO}_{2}$ improved to $99 \%$ and an $\mathrm{FIO}_{2}$ of 1.0 with $10 \mathrm{~cm}$ PEEP, increased $\mathrm{PaO}_{2}$ to $105 \mathrm{mmHg}$.

The patient was transferred to the surgical intensive care unit (SICU) for continued lung ventilation. After two hours, $\mathrm{SpO}_{2}$ decreased to $91 \%$ and $\mathrm{PaO}_{2}$ to 76 mmHg. Repeat CXR showed LLL subsegmental atelectasis and some RML and RLL atelectasis (Figure 3). Repeat bronchoscopy showed some airway oedema with thin secretions aspirated from the right bronchi and thick blood-tinged mucus from the left bronchi.

The patient's respiratory status improved slowly with progressive clearing of bilateral patchy densities. Mechanical ventilation was weaned by the fourth postoperative day with continuation of oxygen therapy and aggressive pulmonary toilet. By day 11 , his $\mathrm{SaO}_{2}$ was 96 to $100 \%$ breathing $\mathrm{RA} ; \mathrm{O}_{2}$ therapy was weaned, and he was discharged some days later.

\section{Discussion}

Intraoperative atelectasis is a rarely reported but impor- 


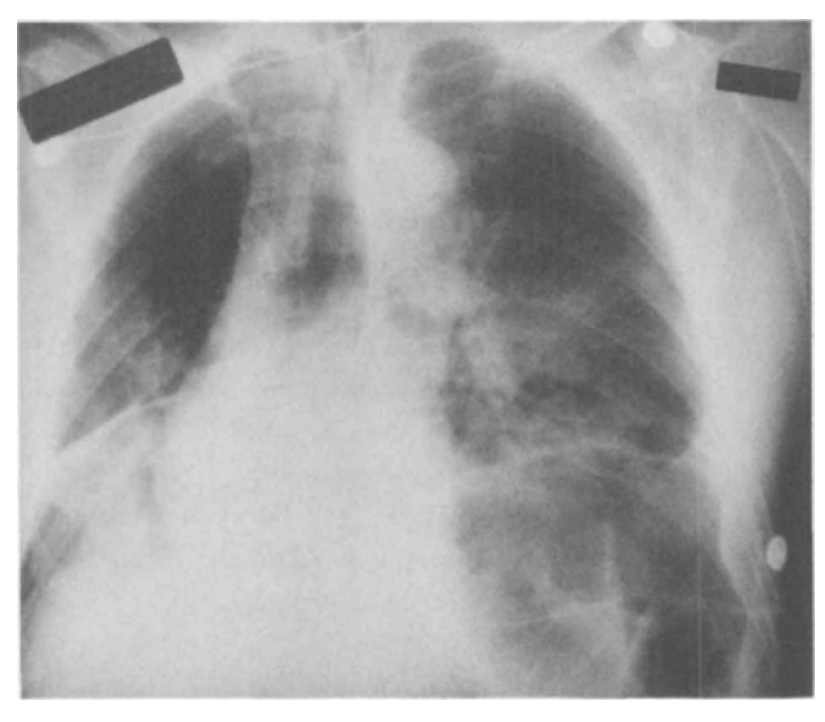

FIGURE 3 Post-bronchoscopy chest $x$-ray in the surgical intensive care unit.

tant event. ${ }^{3-6}$ Our report highlights the often precipitous onset of hypoxaemia associated with considerable pulmonary collapse. Samuels and Brodsky documented patients undergoing orthopaedic surgery following motor vehicle trauma as being at increased risk for this complication. ${ }^{3}$ The hip injury in this patient impeded mobilization and lung expansion despite respiratory therapy and IPPB. Although IPPB has been shown not to prevent postoperative pulmonary complications after abdominal surgery, ${ }^{7}$ this patient may have benefited from more vigorous preoperative preparation including bronchoscopy to attempt re-expansion of the left lung. The congenital eventration of the diaphragm may have predisposed the patient to pulmonary complications although the development of right-sided atelectasis and the fourday period required for weaning from ventilation indicated more widespread involvement. The patient's unexpected hypoxaemia on arrival in the OR after a previously documented $\mathrm{SpO}_{2}$ of $100 \%$ could be ascribed to a combination of sedation given for performance of the epidural block (100 $\mu \mathrm{g}$ fentanyl) and impaired intercostal muscle function with a $T_{8}$ sensory level. A patient with chronic obstructive pulmonary disease who developed right total right lung atelectasis under epidural anaesthesia has been reported. ${ }^{5}$ Functional residual capacity (FRC) is decreased rapidly following induction of general anaesthesia. ${ }^{8}$ Because this would worsen atelectasis and shunt, and because of the patient's suspected gastric distension, it was decided to intubate the trachea to provide IPPV, PEEP and pulmonary toilet to facilitate improved oxygenation. In the lateral position gravity-related perfusion is preferentially directed to the dependent lung. ${ }^{9}$
However, in this patient with airway obstruction to the dependent lung, ventilation was predominantly to the right lung causing an exaggeration of the normal ( $\dot{V}$ ) Q) mismatch induced by anaesthesia and muscle paralysis ${ }^{10}$ leading to an increased shunt and severe hypoxaemia.

Studies of the effects of isoflurane on hypoxic pulmonary vasoconstriction (HPV) have not always provided consistent results. ${ }^{11,12}$ This patient effectively developed one-lung ventilation in the non-dependent lung and HPV might have improved $\dot{V} / \dot{Q}$ matching. The importance of HPV impairment by isoflurane in this patient is unclear as the volatile agent was used at $<1$ MAC and intermittently discontinued at critical periods.

Atelectasis developed despite adequate tidal volumes and PEEP and proved resistant to manipulation of ventilatory pressures and pattern. The reduction in FRC with induction of anaesthesia may be partially reversed with PEEP $^{13}$ with improved ventilation of dependent lung regions. ${ }^{14}$ However, its ability to improve oxygenation considerably during anaesthesia has been questioned..$^{15}$ In the lateral position PEEP forces more perfusion towards the dependent lung ${ }^{14}$ and impedes cardiac output. ${ }^{16}$ As this patient was dependent on an effective $\dot{V} / \dot{Q}$ match in the nondependent lung, the PEEP applied to attempt expansion of the dependent lung worsened the $\dot{V} / \dot{Q}$ mismatch in the nondependent lung. Differential ventilation with selective PEEP to the dependent lung provides better oxygenation. ${ }^{17}$ While theoretically attractive, insertion of a double lumen tube in this patient would have been difficult due to the severe hypoxaemia and lateral position.

The intraoperative hypercarbia in this patient could be ascribed to the relative alveolar hypoventilation (related to increased airway pressures) and increased physiological dead space imposed by a decrease in cardiac output and pulmonary blood flow. The combination of increased alveolar pressure and presumed decrease in pulmonary artery pressure exacerbated the $\dot{V} / \dot{Q}$ mismatch by increasing West's zone I conditions. ${ }^{9}$

Although some secretions were aspirated at initial bronchoscopy the severe hypoxaemia at the time precluded extensive lavage. Clearance of secretions from the dependent lung was also inhibited by gravity and only repeat bronchoscopy, with the patient in the supine position, improved lung expansion and oxygenation.

The primary mechanism of atelectasis in this patient is unclear. Documentation of correct ETT position on initial bronchoscopy would exclude absorption atelectasis due to right endobronchial intubation or unilateral reinflation pulmonary oedema. Although compressive atelectasis due to hydrostatic collection of pleural fluid is a possibility, the rapid clinical deterioration in the lateral position would nullify this as a sole cause. Because of 
predisposing factors to secretion retention, the dramatic response to aspiration and lavage of tenacious secretions at repeat bronchoscopy and the subsequent course with atelectatic changes in the right lung, airway obstruction may have been a factor in the development of the acute atelectasis.

This report highlights a rare but profound cause of intraoperative hypoxaemia. In the patient at risk, strict attention should be given to preoperative preparation and intraoperative positioning. Availability of fibreoptic bronchoscopy to aid diagnosis and management ${ }^{3-5}$ is mandatory as acute collapse may lead to life-threatening hypoxaemia in the OR.

\section{Acknowledgements}

The authors would like to thank Deborah Vinson-Ham for her secretarial assistance in preparation of this document.

\section{References}

1 West JB. Ventilation/Blood Flow and Gas Exchange, 4th ed. Oxford: Blackwell Scientific Publications, 1985; 57.

2 Pedersen T, Viby-Mogensen J, Ringsted C. Anaesthetic pracice and postoperative pulmonary complications. Acta Anaesthesiol Scand 1992; 36: 812-8.

3 Samuels SI, Brodsky $J B$. Profound intraoperative atelectasis. Br J Anaesth 1989; 62: 216-8.

4 Samuels SI, Clark RW. Profound atelectasis during anesthesia. Anesth Analg 1980; 59: 792-5.

5 Marandon JY, Farkas JC. Pulmonary atelectasis after epidural anaesthesia. Ann Fr Anesth Reanim 1990; 9: 312-4.

6 Coroneos NJ, Lawrence J, Torda TAG. Acute massive pulmonary collapse. Anaesthesia 1980; 25: 259-64.

7 Celli BR, Rodriguez KS, Snider GL. A controlled trial of intermittent positive pressure breathing, incentive spirometry, and deep breathing exercises in preventing pulmonary complications after abdominal surgery. Am Rev Respir Dis 1984; 130: 12-5.

8 Brismar B, Hedenstierna $G$, Lundquist $H$, Strandberg $\AA$, Svensson L, Tokics $L$. Pulmonary densities during anesthesia with muscular relaxation - a proposal of atelectasis. Anesthesiology 1985; 62: 422-8.

9 West JB, Dollery Cr, Naimirk A. Distribution of blood flow in isolated lung; relation to vascular and alveolar pressures. J Appl Physiol 1964; 19: 713-24.

10 Klingstedt C, Hedenstierna G, Baehrendtz S, et al. Ventilation-perfusion relationships and atelectasis formation in the supine and the lateral positions during conventional mechanical and differential ventilation. Acta Anaesthesiol Scand 1990; 34: 421-9.

11 Rogers $S N$, Benumof $J L$. Halothane and isoflurane do not decrease $\mathrm{PaO}_{2}$ during one-lung ventilation in intrave- nously anesthetized patients. Anesth Analg 1985; 64: 946-54.

12 Benumof JL, Augustine SD, Gibbons JA. Halothane and isoflurane only slightly impair arterial oxygenation during one-lung ventilation in patients undergoing thoracotomy. Anesthesiology 1987; 67: 910-5.

13 Wyche MQ Jr, Teichner RL, Kallos T, Marshall BE, Smith $T C$. Effects of continuous positive-pressure breathing on functional residual capacity and arterial oxygenation during intra-abdominal operations: studies in man during nitrous oxide and d-tubocurarine anesthesia. Anesthesiology 1973; 38: 68-74.

14 Rehder $K$, Wenthe FM, Sessler $A D$. Function of each lung during mechanical ventilation with ZEEP and PEEP in man anesthetized with thiopental-meperidine. Anesthesiology 1973; 39: 597-606.

15 Bindslev L, Hedenstierna G, Santesson J, Norlander $O$, Gram I. Airway closure during anaesthesia, and its prevention by positive end expiratory pressure. Acta Anaesthesiol Scand 1980; 24: 199-205.

16 Colgan FJ, Barrow RE, Fanning GL. Constant positivepressure breathing and cardiorespiratory function. Anesthesiology 1971; 34: 145-51.

17 Baehrendtz $S$, Klingstedt $C$. Differential ventilation and selective PEEP during anaesthesia in the lateral decubitus posture. Acta Anaesthesiol Scand 1984; 28: 252-9. 